\title{
REVIEWS
}

Estonian Journal of Archaeology, 2006, 10, 1, 89-95

\section{INIMENE, KESKKOND JA MÄLU}

\section{Kristi Grünberg ja Mari Lõhmus}

Kristi Grünberg, Eesti Rahva Muuseum, Veski 32, 51014 Tartu, Eesti; kg@ut.ee Mari Lõhmus, Tartu Ülikooli ajaloo osakonna arheoloogia õppetool, Lossi 3, 51003 Tartu, Eesti; pints@ut.ee

Arheoloogia ja etnoloogia kevadkool 11.-12.03.2006, Taevaskoja

Identiteet sünnib dialoogis teisega: nii sõltub ka teadusharu identiteedi postuleerimine suuresti sellest, kelle suhtes ja kelle jaoks end määratletakse (Kotov 2005, 186). Identiteediloome raamistikku moodustavate ideoloogiate väljendamisel, elluviimisel ja eriti taastootmisel täidab olulist funktsiooni diskursus, kuna ainult keelekasutuses, diskursuses või kommunikatsioonis on võimalik ideoloogiaid selgelt formuleerida (Van Dijk 2005). Kas ja mil viisil on arheoloogia ja etnoloogia diskursused omavahel dialoogis?

\section{Kultuur etnoloogia ja arheoloogia uurimisobjektina}

Tänaseks on nii etnoloogia kui arheoloogia positivistliku (tekstikeskse) paradigma kiiluvees hermeneutikani (kontekstikesksuseni) jõudnud (vt Konsa 2005; Ligi 1995; Vunder 1999). Keskendudes võimalikult üldistele teooriatele, seadis objektiivse reaalsuse olemasolu eeldav positivistlik kultuuriuurimine eesmärgiks sotsiaalsete ja kultuuriliste faktide avastamise, seaduspärasuste väljaselgitamise. Soome arheoloogiast impulsse saanud ajaloolis-geograafilises meetodis kasutati algul evolutsionismi (kultuuri arengu) ja hiljem difusionismi (kultuuri leviku) teooriat. Kui arheoloogid tähtsustasid ajalisi variatsioone, siis etnoloogide jaoks olid olulised ruumilised erisused.

Milline on aga arheoloogia ja/või etnoloogia tänapäeva Eestis? Homogeensete teaduste asemel on tegemist pigem pluralistlike distsipliinidega, mille uurimissuundi ühendab kõige üldisemas mõttes inimene, püüd mõista. Viimast tõdesid ka arheoloogia magistrandid oma projektis: minevikku on tasapisi tekkimas tegutsev ja otsustav, tundev ja uskuv - elus inimene (Konsa jt 2003, 90). Kui etnoloogil on võimalik pöörduda inimese kui mõtleva, tegutseva ja kultuuri loova indiviidi poole, siis arheoloogil see võimalus puudub. Muistset inimest, keda arheoloogid uurivad, enam ei ole, on vaid fragmentaarsed jäänukid materiaalsest kultuurist. Kultuur, mille uurimisega nii etnoloogia kui ka 
arheoloogia tegelevad, on heterogeenne (tuleneb inimese tegutsemisest ja loovusest), viimane omakorda aga teeb kultuurist keeruka uurimisobjekti (Torop 2005, 113). ${ }^{1}$ Antropoloog Clifford Geertzi (1973) järgi on kultuur inimese käitumises ja tegevuses, ideedes ja mõtlemises manifesteeruv tähenduste süsteem. Nii lähtubki antropoloogiline (inimkeskne) etnoloogia kultuurist kui konkreetsest miljööst ja loojatest sõltuvast kommunikatsiooni- ja vahendusprotsessist. Kausaalsete diakrooniliste selgituste asemel on huviobjektiks sotsiaalne kontekst, konkreetne aeg ning ruum ja inimene kultuuriloojana. Fenomenoloogilise käsitluse põhiliseks meetodiks on hermeneutika - tähendust omava materjali interpreteerimine eesmärgiga mõista.

1990. aastatel tõi tõlgendav-hermeneutiline lähenemine muudatusi ka senistesse arusaamadesse arheoloogiateadusest. Hermeneutika annab võimaluse selgitada muistse mõtteviisi ja materiaalse kultuuri seost (Ligi 1995, 197). Materiaalset kultuuri vaadeldakse mitte lihtsalt kui inimese loodut, vaid kui tähenduslikult moodustatut ja inimese poolt mõtestatut (Konsa 2005). Kui seni seletati materiaalses kultuuris toimunud muutusi murrangutega majandusviisis, sotsiaalsetes ning omandisuhetes, ideoloogias ning religioonis, siis nüüd hakati kalduma seisukoha poole, et ühiskonna erinevate aspektide muutused ei toimu ühesuguse intervalliga (Konsa jt 2003, 89-90).

Kuidas käsitletakse etnoloogia- ja arheoloogiateaduses inimest? Milline on (olnud) tema roll (minevikus)? Kuidas ja miks uuritakse ajalooteadvust? Millised on nende terminite ja teemade kattuvused arheoloogias ja etnoloogias?

Nimetatud küsimustele otsiti vastust 11. ja 12. märtsil Taevaskojas toimunud arheoloogia ja etnoloogia kevadkoolis. Seminari eesmärgiks oli oma vaadete, meetodite ja uurimisprobleemide tutvustamine teise teadusharu esindajatele, s.o senisest aktiivsema kommunikatsiooni tekitamine kahe distsipliini vahel, konstrueerides nii teadlaskonna kui sotsiaalse rühma identiteeti. ${ }^{2}$ Sügistalvistel kokkusaamistel jõuti ühise arutelu tulemina teemani "Inimene, keskkond ja mälu", mis andis noortele uurijatele oma vaadete, meetodite ja konkreetsemate uurimisülesannete avamiseks piisavalt laiad raamid.

\section{Mälu ja keskkond uurimisainesena}

Kui etnoloogide jaoks on mälu fundamentaalne meedium, allikas ja vahend kultuuri kirjeldamiseks (Kõresaar 2003,7), siis Eestis on nimetatud temaatika esialgu veel arheoloogiakaugeks jäänud. ${ }^{3}$ Kuna aga see, mida inimesed mäletamisväärseks peavad, sõltub nende kultuurilisest taustast, olevikusituatsioonist, siis ei saa ka arheoloogia mälust kui sotsiaalsest fenomenist ei üle ega ümber. Millised kategooriad olid olulised minevikus? Millised olid need kultuurilised tegurid, mis mõjutasid minevikus seda, mida mäletada?

Olles osa identifitseerumise protsessist (Van Dijk 2005), seob mälu identiteedi kujunemise ajalooga ja vastupidi (Kõresaar 2003, 9). Individuaalse ja kollektiivse mälu kontseptsiooni autor prantsuse sotsioloog ja antropoloog Maurice Halbwachs tõlgendas mälu kui mineviku kollektiivset rekonstruktsiooni. Indiviidid mäletavad, ent ühiskond määrab tegelikult selle, mida mäletada, mis

1 Lähtudes Paul Feyerabendist, ei ole maailmas olemas üht õiget kultuuri uurimise viisi. Rangelt võttes on ka teaduslik lähenemine kultuurile vaid üks võimalus, mis ei välista omakorda teisi tõlgendusi ja viise enda kõrval (Torop 2005, 113).

2 Sotsiaalse rühma identiteedi konstrueerimise tasandid: 1) rühmasisene diskursus - sellest sõltuvad rühma parajasti käsil olevad tegevused, taastootmine ja ühtsus; 2) rühmadevaheline diskursus - rühmade ja nende liikmete huvideks on eneseesitlus, enesekaitse, legitimeerimine, veenmine, uute liikmete värbamine (Van Dijk 2005, 150).

3 Samas ei saa mööda vaadata üksikutest tekstidest, kus mäletamisele ja mälule Eesti muinasajal riivamisi viidatakse (vt nt Lang 2005). 
on mälestusväärne ja kuidas seda tuleb mäletada. Seega on mälu alati selektiivne. ${ }^{4}$ Samastades end oma rühmale oluliste avaliku elu sündmustega, mäletatakse paljugi sellist, mida pole isiklikult kogetud (Burke 2003, 70). Kollektiivses mälus toimub pidev dialoog erinevate aegade, reaalsuste, kogemus- ja tõlgendussüsteemide vahel. Nii on kollektiivne mälu protsessuaalne ja dünaamiline, järjepidevust loov, aja- ja kohaspetsiifiline (Kõresaar 2003, 10).

Jan Asmanni järgi fikseerib mälestusi avalik mälukultuur - komemoratsioon, mille tulemusena tekivad toetuspunktid ehk mälestusmärgid, millest edaspidi saavad omakorda kultuurimälu tugipostid (Kõresaar 2001, 44-45). Arheoloogiamagistrant Silja Kalle käsitles ettekandes "Mälust kirjaeelsetes kultuurides" mälu ja mäletamise probleemi mineviku ühiskondades, otsides vastuseid küsimusele, kuidas kogukonna mälu (kollektiivne mälu) on mõjutatud ühiskonna kõrgemate institutsioonide poolt. Arheoloogias (kirjaeelsetes kultuurides) saab mälu nähtavaks materiaalsetes objektides, kajastades põlvkondi kestvaid traditsioone või siis nende katkemist. ${ }^{5}$ Halbwachsi järgi on ruum samuti üks mälu edasikandmise vahendeid. Meelespidamisväärseks peetavad kujundid paigutatakse mõjusatesse kujutluspaikadesse, et kasutada seeläbi tekkivaid ideede assotsiatsioone (Burke 2003, 73). Ettekandes esitletule järgnes elav arutelu, mille käigus tõstatati küsimusi paikade tähenduse muutumise seosest mäluga, näiteks: miks me leiame kivikirstkalmete alt nöörkeraamika kultuuri asulakohti? Miks on kivikirikud rajatud muistsetele kultuskohtadele või nende vahetusse lähedusse? Kuidas neid fenomene interpreteerida?

Kristi Grünberg jätkas oma ettekandega “Ajaloopilt identifikatsioonimarkerina: vene multikate põlvkond" mälu temaatikat, keskendudes küsimusele identiteediloomest. 30-aastaste kohordi, nn vene multikate põlvkonna varal püüdis etnoloogiatudeng visandada muutused rühma identiteedis ja kirjeldada selle aluseks olevat ajaloopilti. Väljendades kollektiivset arusaama ajaloolisest reaalsusest, on ajaloopildid teadmised ühisest ajalikkusest ja sel moel oluliseks osaks rühmaidentiteetide kujunemisel (Heins 1993, 63). Allikmaterjalina kasutatud Andrus Kivirähki näidendit "Helesinine vagun", selle lavaversiooni ja Taago Tubina lavastust ümbritsevaid tekste, st teatrikriitikat analüüsides lähtus uurija etendusest kui kommunikatsiooniaktist, arvestades selle dialoogi ümbritseva sotsiaalse ruumiga. Teatrietendusele võib samuti läheneda kui mäletamisrituaalile - mineviku taasesitusele, mälestusaktile, mis on samal ajal ka katse suruda peale mineviku tõlgendusi, vormida mälu ja sel teel kujundada ühiskondlikku identiteeti (Burke 2003, 73). Seminaris osalenute isiklik seotus ja ühine kogemus põhjustas ettekande järel laiapinnalise diskussiooni, mille käigus püüti muu hulgas piiritleda vene multikate põlvkonnaks nimetatavat inimrühma.

Ajaloomagistrant Lembi Sepp ja -tudeng Jüri Metssalu tegelesid oma ettekannetes mälu(pärand)maastike ${ }^{6}$ ning pärimuskultuuriga, tuues esile kaks erinevat võimalust meid ümbritseva

${ }^{4}$ Nii on see, mida me minevikust mäletame, seotud otseselt teadlaste tegevusega, sh arheoloogide tööga (ajaloopildi (re)konstrueerimine). Sõltub ju see, milliseid muistiseid me maastikul eristame ja kaevame, uurija (teaduslikust) taustast ja eelteadmistest. Läbi metodoloogilise valiku mäletame kirjalike allikatega katmata minevikust vaid mingit osa (sellest, mis maapõues säilinud on).

5 Nt on Richard Bradley analüüsinud paelkeraamika kultuuride aegset pikkmajade ehitamise traditsiooni Edela-Euroopas (nt Cuiry-les-Chaudares'i asulakoht Põhja-Prantsusmaal). Uurimistulemustest johtus, et pärast elamu hülgamist ehitati see mujale, jälgides eelmisega samasugust orientatsiooni. Tõenäoliselt peeti meeles mahajäetud elamu asupaika, vaatamata sellele et maapealsed struktuurid polnud enam jälgitavad. Nii anti läbi küllalt püsiva meediumi edasi kogukonna sotsiaalset mälu, rõhutades seeläbi ka juurte müüti (Bradley 2002, 25, 47).

${ }^{6}$ Uudseks aspektiks inimese ja keskkonna suhete analüüsil kujunes 1990. aastatel kultuurmaastiku mõiste (vt Lang 1999; 2000: kultuurmaastik on pidev protsess, kus pühitsetud ning pühitsemata aeg ja ruum on ühiskonna religioossete, ideoloogiliste ja sotsiaalsete suhete manifestatsiooniks füüsilises maastikus). Inimese ja keskkonna suhetesse on sisse toodud religioosne ja mentaalne aspekt (Konsa jt 2003, 88-89). 
keskkonna uurimiseks. Aktiivse kultuurilooja ja -kandjana annab inimene ruumile tähenduse, täidab selle subjektiivse sisuga. Nii on ruum teadmiskultuur, milles põimuvad ja ristuvad erinevatelt ootushorisontidelt (st erinevatest sotsiaalsetest ja kultuurilistest taustsüsteemidest) pärit infoväljad. Kognitiivse kultuuriuurimise huvi keskmes seisab inimene oma isikliku aja ja ruumi loojana. Nii peatus Lembi Sepp ettekandes "Arheoloogia ümbritsevas maastikus. Mälupaigad: Rebala, Keava, Kivisaare" suures osas küsimustel: kuhu paigutuvad arheoloogilised väljakaevamised ja nendega seotud paigad lähiümbruses elavate inimeste mõttemaailmas? Kuidas mõtestatakse ümbritsevat maastikku, kuhu koonduvad mälupaigad? Kohalike inimeste kohatunnetust ja mineviku mõtestamist kajastab hästi ettekandes väljatoodud tsitaat ühest intervjuust: "Ja siis oli see arheoloog Vello Lõugas. Tema hakkas Rebala küla hirmsasti päästma. Lõugas ei saanud muud moodi hakkama, siis pani küla muinsuskaitse alla ja hakkas neid kalmeid siia tegema" (naine, sündinud 1931, Harju maakond, Rebala küla). Kohatunnetuse kujunemise protsess on jälgitav vaid siin ja praegu.

Ajalootudeng Jüri Metssalu keskendus ettekandes "Pärimusmaastiku uurimisseisust ajaloolisel Lõuna-Harjumaal" kohapärimusele kui interdistsiplinaarsele uurimisteemale, tutvustades ühtlasi 2004. aastal läbiviidud Raplamaa (Rapla, Juuru ja Hageri kihelkond) kohapärimuse kogumise ning uurimise projekti ja sellega seoses esilekerkinud küsimusi (dateerimine, pärimuse seotus ajalooliste sündmuste, pärimusekandja isiku ja tema elulooga, kasutatud terminid jne). Nii etnoloogiat, arheoloogiat kui ka folkloristikat siduvaks faktoriks mälu(pärimus)maastike uurimisel on koht. Püüdes jutustada paiga lugu, kõnelevad uurijad ka praeguste ja minevikus elanud inimeste lugu, kuna inimene ja teda ümbritsev keskkond on pidevas vastasmõjus. Ühe probleemina tõi Jüri Metssalu välja küsimuse uurija ja uurimissituatsiooni võimalikust mõjust kogutud materjalile. Sama temaatika kerkis esile ka pärast Lembi Sepa ettekannet. Uurijat ei ole võimalik elimineerida, tema kohaloluga tuleb arvestada nii kogumis(intervjuu)situatsioonis kui hilisemates tõlgendustes. Vastukaja leidis ka kohapärimuse ekspluateerimist ja kaitset puudutav küsimus. Turism küll väärtustab pärimust, on selle levikukanaliks, kuid ärihuvisid silmaspidav meelelahutusega manipuleerimine viib koha n-ö puutumatuse, eheduse kadumiseni.

Artiklis "Mõistmisest ja teisest antropoloogias" on Toomas Gross välja toonud Melville Herskovitsi definitsiooni kultuurist kui inimese poolt tehtud osast keskkonnast, mis on küll tabav, ent mitte ammendav $(1996,1718)$. Kuid just sellisel kultuurikeskkonnal peatus arheoloogiamagistrant Mari-Liis Rohtla, lahates muuseumi kui tehiskeskkonna küsimust. Ettekanne "Muuseum kuulub..." puudutas võrdselt nii arheolooge kui etnolooge. Muuseumi ülesandeks on anda inimesele võime näha pärandit, ajalugu oma igapäevases elus. ${ }^{7}$ Tõstatunud probleemid käsitlesid nii meelelahutuse ja tõsiteaduse vahelist rajajoont, ehedate esemete ja koopiate vahekorda kui ka läbielamise rolli (viljajahvatamine, eksperimentaalarheoloogia) teadmiste kinnistajana nn sure muuseumi lugema õppimisel. Kui kaugele võib muuseumides eksponeeritava atraktiivse(ma)ks muutmisel, põnevuse ja pinge kruvimisel minna (näiteks poodud vahakujud Toweris), et ei kaoks side esemetega? Muuseumi põhitrumbiks on ju ehe ja originaalne artefakt (näiteks selle asemel et minna muuseumisse Mona Lisa koopiat vaatama, ostab inimene endale pigem juba isikliku koopia (posteri)). Rahvusvahelise Muuseumide Nõukogu (ICOM) definitsiooni järgi on muuseum mittetulunduslik, püsiv, ühiskonna teenistuses ja juhtimise all olev publikule avatud asutus, mis kogub, säilitab, uurib, tutvustab ja eksponeerib uurimise, harimise ja meelelahutuslikul eesmärgil materiaalset tõestusmaterjali inimese ja keskkonna kohta. Muuseumi sünergia tulenebki sellest, kui kõik need funktsioonid on normaalselt välja arendatud.

${ }^{7}$ Nii on museoloog Kenneth Hudson võrrelnud nt Euroopat suure muuseumiga, kus iga ehitis, iga põld, jõgi ja raudtee kannab endas sõnumit oma maast ja minevikust, kui vaataja teab, mida näeb. Siin-seal selles suures muuseumis on asutusi, mida kutsume muuseumiks. Nende peamine ülesanne on aidata inimesi mõista suurt muuseumi (Tvauri 2003). 


\section{Tehnoloogiatest ja inimesest selle taga}

Tehnoloogia pole pelgalt miski, mis eksisteerib iseenesest, see on alati enamat kui protseduuride kogum, mis muudab maailma füüsilist vormi. Näiteks ei seisne jahipidamine oskuslikus vibu ja noole käsitsemises (meeste töö) ega heade jahikoerte treenimises (naiste töö). Sisaldades neid mõlemaid, hõlmab see spetsiifilisi teadmisi ja oskusi, ühtlasi võimeid ja võimalusi seada sisse vajalikke suhteid tapetava looma vaimuga (Gosden 2005, 162). Paljuski on tehnoloogiaid, kaubandust ja artefakte uurivate Eesti arheoloogide huvid instrumentaalset laadi, suunatud funktsioonianalüüsile ja positivistlikust metodoloogiast lähtuvad (Konsa 2005). Kuigi materiaalse kultuuri ja tehnoloogiate kirjeldamine ja analüüsimine on üks etnoloogia klassikalisi uurimisvaldkondi, käsitlesid seda temaatikat kevadkoolis arheoloogid, kelle ettekanded ei piirdunud pelgalt tehnoloogiliste protsesside illustreerimisega. Arheoloogiamagistrant Riina Rammo pöördus ettekandes "Pronksspiraalkaunistuste valmistamisest Eesti aladel muinasaja lõpul ja keskaja alguses" pronksspiraalkaunistuste tootmisprotsesside kirjeldamise kõrval nende valmistajate ehk meistrite küsimuse juurde. Kes olid need inimesed, kes selliseid kaunistusi valmistasid? Kas ja miks oli tegemist spetsialiseerunud käsitööharuga? Hiljemalt 10. sajandist levinud pronksspiraalkaunistused olid tehtud imporditud hinnalisest toormaterjalist, sealjuures hõlmas tootmisprotsess ühtlasi mitut käsitööala (toormaterjali töötlemine ja spiraalkaunistuste valmistamine). Samuti kerkisid esile küsimused meistri teeninduspiirkonna, sotsiaalse positsiooni ja sotsiaalse soo kohta (mees või naine), käsitööalast kui iseseisvast elatusallikast (mh miks mõni tehnika on kandunud kuni 20. sajandi alguseni?).

Tootmisprotsessiga tegelesid ka arheoloogiamagistrant Tanel Saimre ja TÜ õppejõud Andres Tvauri: "Lubja- ja tõrvatööstuse arheoloogia". Et kõnealune projekt on alles algusjärgus ${ }^{8}$, esitati kevadkoolis läbi uurimisajaloo tutvustamise (näiteks etnoloog Mihkel Leetmaa 19.-20. sajandi lubja- ja tõrvatööstuse käsitlused) edasise töö eesmärgid ning probleemid. Vaatluse alla võetakse kogu süsteem: logistika, mis kaasneb valmistamise, turustamise ja kasutamisega. Huvi möödunud aegade tehnoloogia ning tootmisprotsesside ja nende ühiskondliku mõju vastu on kasvanud ka tänapäeval kasutatavate loodusteaduslike meetodite läbi avanevate võimaluste tõttu. Millal hakati Eestis tõrva ning tökatit ajama ja tootma? Kas aja jooksul (muinasajast uusajani) on nii lubja- kui ka tõrvatööstuses toimunud tehnoloogilisi muutusi? Kas ja millised on piirkondlikud erinevused? Milline on tööndusliku tegevuse sotsiaalne funktsioon? Pikemas perspektiivis soovitakse tõrva- ja lubjatööstuse uurimisse haarata teistegi teaduste (näiteks etnoloogia, ajalugu) esindajaid.

Madis Rennu "Kivid aias nagu rosinad saias. Muljeid-mõtteid-intervjuukatkeid suvistelt kiviaia välitöödelt" vaatles Virtsu lähedal asuva Rame küla kiviaedu. Lisaks aedade ehituse tehnoloogilise külje, funktsiooni ja kohalikest loodusoludest tingitud tööriistade ning -võtete vaatlusele tõi etnoloogiamagistrant välja ka kiviaia erinevaid rolle endisaegses elukorralduses. Sarnaselt lubjaja tõrvatööstust käsitlenud ettekandele keskenduti siingi küsimustele kiviaedade piirkondlikust eripärast, nende ehitamise traditsiooni algusest. 2005. aasta välitöödel talletati ka kiviaedadega seotud pärimust. Kes rajasid kiviaedu - kas iga mees sai selle tööga hakkama või olid nende ehitamiseks kindlad meistrid? Arutelu käigus tõdeti, et kiviaedade vanuse Eestis võib tagasi viia vanimate põllupeenardeni, seega kuni 3000-2000 aasta taha. Vaatamata sellele et edasine uurimine on funktsionalistlikku laadi, pidas autor aedadest endist olulisemaks nende vahel elavat inimest oma vajaduste, eelistuste ja maitsega.

Kui tehnoloogiaid käsitlenud ettekannetes pöörati sotsiaalsetele suhetele põgusat tähelepanu, siis etnoloogiamagistrandid Maarja Kaaristo ja Reet Ruusmann võtsid luubi alla sotsiaalsed

\footnotetext{
8 Seni pole Eestis tööstusarheoloogiaga tegeldud. Kuna tõrva- ja lubjatööstusega seotud tootmismuistised on arheoloogiliselt uurimata, vajab traditsioonilise töönduse objektide otsimise, kaevamise ja uurimise metodoloogia alles väljatöötamist.
} 
suhted etnoloogia uurimisprobleemina. Neist esimene vaagis oma ettekandes "Sotsiaalne stratifikatsioon ja Eesti külaühiskond" Nursi vallakohtu materjalidele (1868-1911) põhinedes sotsiaalset stratifikatsiooni ${ }^{9}$ ületavaid kohtuvaidlusi. Baseerudes õigusetnoloogilistele uurimustele, pole õigus etnoloogile niivõrd autonoomne institutsioon kui ühe kultuuri olemuslik ja orgaaniline osa. Seega on oluline üksikjuhtumi uurimine sotsiaalset konteksti arvestades, samuti inimkäitumise uurimine, mida aktsepteeritakse ja kasutatakse üldiselt mingis sotsiaalselt defineeritud kogukonnas, kui see puudutab seaduse teemat. Õigusetnoloogi Simon Robertsi välja töötatud tüliküsimuste sotsiaalse stratifikatsiooni skaalat (vt Kaaristo 2005) kasutades käsitleti nimetatud juhtumeid.

Arheoloogile on kättesaadavad vaid esemed, sageli fragmendid, mis ei pruugi olla oma esialgses kasutuskontekstis. Etnoloog võib aga ligi pääseda ka eset ümbritsevatele (kultuuri)tekstidele, mis võimaldavad jälgida artefakte kui sotsiaalsete kategooriate väljendajaid. Nii pühendas Reet Ruusmann oma ettekande "Asjad sotsiaalsete kategooriate väljendajatena" asjade võimele konstrueerida identiteeti. 1990. aastate esemeuurimise keskmes on inimesed, kes tegelikult materiaalseid objekte valmistavad, omavad ja kasutavad. Materiaalse kultuuri uurimisele võib läheneda ka kui inimestevaheliste sotsiaalsete suhete analüüsimisele selle kaudu, kuidas indiviidid konstrueerivad oma materiaalset ümbrust. Kokkuvõtvalt tõdeti, et esemed iseenesest ei oma tähendust, see luuakse alles nende kasutamise käigus - ühelt poolt nad ilmalikustavad kõige aluseks olevad kultuurilised kategooriad, teisalt positsioneerivad inimesi sellesse vastavalt kellegi käitumisharjumustele.

\section{Kokkuvõte}

Seminari ülesandeks ei olnud anda tõstatatud probleemidele terviklahendeid, pigem püüti esitatud materjali ja küsimustega ärgitada kaasa mõtlema ja nendel teemadel arutlema. Olenemata ühise keele olemasolust praegusel ajahetkel, muutuvad ka siin pakutud tõlgendused ajas ja ruumis koos muutustega kultuuris, millesse tõlgendaja kuulub. Etnoloogiat ja arheoloogiat võib ka vaadelda kui kaht kultuuri, mis pole küll unitaarsed, ent moodustavad just nagu hõimude konföderatsiooni. Omades piisaval määral ühist sõnavara (sarnast keelt), jõutakse vähemalt aeg-ajalt omavahel kokkuleppele õige tegutsemise vormi ja protsessi osas. Viimane teeb niisiis võimalikuks etnoloogiaja arheoloogiateaduse vahelise kommunikatsiooni (Gosden 2005, 35), mille üheks tunnistajaks oli ka toimunud kevadkool.

\section{Kasutatud kirjandus}

Bradley, R. 2002. The Past in Prehistoric Societies. London; New York.

Burke, P. 2003. Ajalugu kui ühiskondlik mälu. - Vikerkaar, 10-11, 69-83.

Geertz, C. 1973. The Interpretation of Cultures: Selected Essays. New York.

Gosden, C. 2005. Anthropology and Archaeology: A Changing Perspective. London; New York.

Gross, T. 1996. Mõistmisest ja teisest antropoloogias. - Akadeemia, 8, 1717-1738.

Heins, F. 1993. Über Geschichtsbilder in Erinnerungerzählungen. - Zeitschrift für Volkskunde, 89, 66-77.

Honko, L. \& Pentikäinen, J. 1997. Kultuuriantropoloogia. Tallinn.

Kaaristo, M. 2005. Peksmine ja löömine Eesti külas 1868-1911 Nursi vallakohtu protokollide näitel. Õigusetnoloogiline perspektiiv. - Mäetagused, 27, 31-46.

Konsa, M., Ilves, K., Jonuks, T., Kiudsoo, M., Ots, M., Saluäär, U. \& Sarv, K. 2003. Missugune sa oled, Eesti arheoloogia? - EAA, 7: 1, 72-94.

9 Ühiskond on ühiste eesmärkide poole pürgivate inimeste sotsiaalne süsteem, mis koosneb eri asenditest - staatustest (Honko \& Pentikäinen 1997, 43). 
Konsa, M. 2005. Tee normaalteadusest normaalseks teaduseks: Eesti arheoloogia suundumusi 1990. aastatel. - Õpetatud Eesti Seltsi aastaraamat, 2003. Tartu, 94-115.

Kotov, K. 2005. Kultuur, identiteet ja enesekirjeldus. - Acta Semiotica Estica, II, 184-192.

Kõresaar, E. 2001. Kollektiivne mälu ja eluloouurimine. - Kultuur ja mälu. Konverentsi materjale. (Studia ethnologica Tartuensia, 4.) Tartu, 42-58.

Kõresaar, E. 2003. Mälu, aeg, kogemus ja eluloouurija pilk. - Mälu kui kultuuritegur: etnoloogilisi perspektiive. (Studia ethnologica Tartuensia, 6.) Tartu, 7-32.

Lang, V. 1999. Kultuurmaastikku luues. Essee maastiku religioossest ja sümboliseeritud korraldusest. - EAA, 4: 1, 63-85.

Lang, V. 2000. Keskusest ääremaaks. Viljelusmajandusliku asustuse kujunemine ja areng VihasooPalmse piirkonnas Virumaal. (MT, 7.) Tallinn.

Lang, V. 2005. Inimene, kultuur ja loodus muinasajal. - Eesti looduskultuur. Koost T. Maran \& K. Tüür. Tartu, 11-28.

Ligi, P. 1995. Ühiskondlikest oludest Eesti alal hilispronksiajal ja rauaajal. - Eesti arheoloogia historiograafilisi, teoreetilisi ja kultuuriloolisi aspekte. Toim V. Lang. (MT, 3.) Tallinn, 182-270.

Torop, P. 2005. Peeter Toropi järelsõna eestikeelsele väljaandele. - Kultuuride analüüs. Tõlk E.-R. Soovik. Tallinn, 311-315.

Tvauri, A. 2003. Museoloogia ja muinsuskaitse. Õppematerjal (veebruar 2003). http://www.arheo.ut.ee /Museo\&muinsus.pdf.

Van Dijk, T. A. 2005. Ideoloogia. Multidistsiplinaarne käsitlus. Tartu.

Vunder, E. 1999. Muutuv eesti etnoloogia. - Ajalooline Ajakiri, 1 (104), 31-42. 